\title{
Experimental and Theoretical Study on Three Combustion Models for the Determination of the Performance Parameters of Nitrocellulose - Based Propellants
}

\author{
TITI PARASCHIV ${ }^{1}$, TUDOR VIOREL TIGANESCU ${ }^{1 *}$, GEORGE OVIDIU IORGA $^{1,2}$, \\ RALUCA ELENA GINGHINA ${ }^{2}$, OCTAVIAN CONSTANTIN GRIGOROIU ${ }^{1}$ \\ ${ }^{1}$ Military Technical Academy, Faculty of Mechatronics and Integrated Armament Systems, 39-49 George Cosbuc Blvd., \\ 050141, Bucharest, Romania \\ ${ }^{2}$ Scientific Research Center for CBRN Defense and Ecology, 225 Soseaua Oltenitei, 041309, Bucharest. Romania
}

\begin{abstract}
Nitrocellulose based propellants are the main materials used for ballistic and rocket applications. The chemical composition of the propellants, the loading density and propellant grain geometry are the decisive parameters that influence the performance parameters in ballistic application. In this paper the authors evaluate three models of combustion for energetic materials for the determination of heat of explosion and specific volume together with the adiabatic flame temperature. The authors select six types of propellant (two simple base propellants, two double base propellants based on nitroglycerine and two triple base propellants based on nitroguanidine) and the authors determined the heat of explosion and specific volume using a bomb calorimeter and a Julius-Peters device. The results obtained from the combustion models were compared to the experimental results and assumptions were done on the influence of pressure and temperature on the chemical composition of combustion gases produced by the confined deflagration of nitrocellulose-based propellants.
\end{abstract}

Keywords: propellants, combustion models, Lagrange multipliers, modelling, chemical equilibrium.

\section{Introduction}

Ballistic propellants are designed to exhibit fast combustion or deflagration in confined conditions in order to produce a large quantity of gases at high temperature, thus producing mechanical work in order to propel a projectile inside a barrel or to produce thrust for the movement of a rocket. The main performance parameters of a propellant are burn rate, heat of explosion, volume of gases and flame temperature. Depending of the shape of the propellant grain and the loading density, the combustion or deflagration process can take place in milliseconds, for guns and artillery or $0.3-10 \mathrm{~s}$ for the whole burning time of rocket motors.

Nitrocellulose based propellants (NCP) are the main materials used in producing mechanical work for propulsion of ammunition and rocket/missiles. The main advantages of NCP over polymer matrix energetic particle propellants, known as composite propellants, are related to the high energy content, fast burning rate and very good mechanical properties [1,2]. The use of stabilizers like diphenylamine (DPA), 1,3-diethyl-1,3-diphenylurea (Centralite I) or 1-methyl-3,3-diphenilureea (Akardite II) gives them good chemical stability for 20 to 30 years of service [3, 4]. Simple base propellants (SBP), which have $80-98 \%$ cellulose nitrate ester (nitrocellulose - NC) as energetic component, gelled with ethanol or diethyl ether, are used in large caliber artillery shells, while double based propellants (DBP), colloids with energetic materials like propane-1,2,3-triyl trinitrate (nitroglycerine-NG), 1,2-dinitroxyethane (ethylene glycol dinitrate - EGDN) and nitric acid 2-(2-nitrooxyethoxy)ethyl ester (diethylene glycol dinitrate - DEGDN) as plasticizer for NC are used for rocket propulsion, medium and small caliber artillery and for small arms. Triple base propellants (TBP) are composites of NC, NG and 1nitroguanidine (NQ).

*email: tiganescu.viorel.t@gmail.com 
The role of NQ is to provide additional energy for propulsion, while keeping a moderate flame temperature. The nitrocellulose used in SBP and DBP has a degree of nitration of 13.15-13.25\% (14.14 $\%$ is the maximum theoretical nitration degree) while TBP use a lower nitrogen content NC, in between 12.2-12.6\% [2, 5]. Other than energetic components, the NCPs can contain burn rate modifiers, stabilizers and additives. The role of burn rate modifiers is to lower the combustion rate in progressive burning geometry grains. Camphor is mainly used, but also phthalates and 1-methyl-2,4-dinitro benzene (dinitro toluene - DNT), especially SBP. Stabilizers are used in NCP to consume the nitric acids formed by the decomposition of $\mathrm{NC}$, in order to avoid the autocatalytic reaction of denitration. Additives like potassium salts are used in NCP to lower the flame temperature while vaseline and vaseline oil are used to improve workability. Graphite is used on the surface of the NCP grains as lubricant and to lower the friction, flame and electrostatic sensibility of the propellants [6].

For the determination of the chemical composition of the combustion products and the energetic performance of the propellants, burn models have been designed. Some models are semi empirical, for combustion of CHNO (carbon, hydrogen, nitrogen oxygen) propellants, while other complex thermochemical codes that can compute complex propellants, containing metal additives or inorganic salts [7]. The chemical composition of the combustion products is dependent of the chemical composition of the propellant ingredients, but it can be influenced by the loading density of the combustion chamber. Determination of the chemical composition of the combustion products enables determination of the main performance parameters of propellants, which are heat of explosion, volume of gases and adiabatic flame temperature. The first two parameters should be maximized, while a high flame temperature can have adverse effects on the artillery system or the combustion chamber of the rocket motor [8].

Six types on NBP have been investigated using three combustion models and experimental determination of heat of explosion $\left(\mathrm{Q}_{\mathrm{e}}\right)$ and volume of combustion products $\left(\mathrm{V}_{\mathrm{e}}\right)$.

\section{Materials and methods}

\subsection{Nitrocellulose based propellants}

Six types of nitrocellulose-based propellants (NBP) were chosen for the experimental part of the work, two simple based propellants, named SB1 and SB2, two double base propellants DB1 and DB2, having 8.74 and $11.43 \%$ nitroglycerine (NG), respectively, and two types of triple base propellants, TB1 and TB2, having 54.70 and $47.70 \%$ nitroguanidine (NQ), respectively. The aspect of the selected propellants is shown in Figure 1. It is observable the surface treatment with graphite of SB2, DB1, DB2 and TB2. The geometry of the propellant grain is very different, being in relation with the use of the propellant. The double base propellants (DB1 and DB2) are used for small arms ammunition while the big grain SB1 is used for large caliber artillery ammunition. In Table 1, the chemical composition of the propellants is presented.

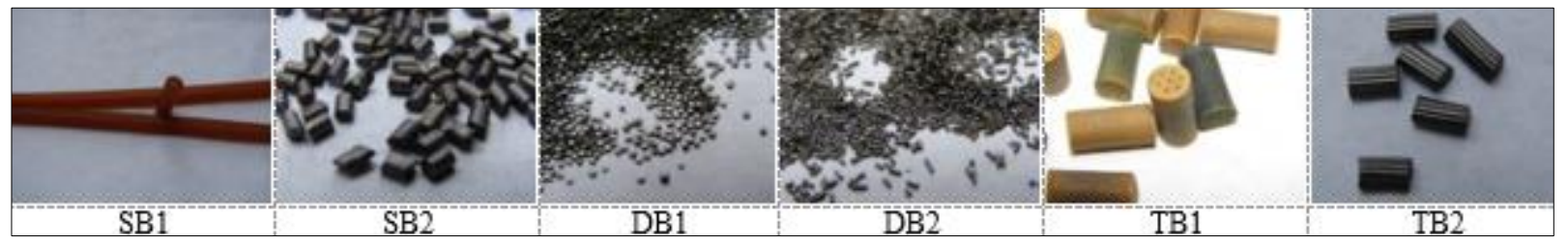

Figure 1. The aspect of the propellants used for determination of $Q_{e}$ and $V_{e}$

Table 1. Chemical composition of the propellants used for determination of $Q_{e}$ and $V_{e}$

\begin{tabular}{|c|c|c|c|c|c|c|c|c|c|}
\hline Propellant & $\begin{array}{c}\text { Theoretical } \\
\text { maximum } \\
\text { density } \\
\left(\mathrm{kg} / \mathrm{m}^{3}\right)[9]\end{array}$ & $\begin{array}{c}\text { Equivalent } \\
\text { chemical formula }\end{array}$ & $\begin{array}{c}\text { Heat of } \\
\text { formation } \\
\left.\mathrm{H}_{\mathrm{f}}, \mathrm{kJ} / \mathrm{mol}\right) \\
{[9]}\end{array}$ & $\mathrm{SB} 1$ & $\mathrm{SB} 2$ & $\mathrm{DB} 1$ & DB2 & TB1 & TB2 \\
\hline Components & 1.662 & $\mathrm{C}_{6} \mathrm{H}_{7,36} \mathrm{~N}_{2,64} \mathrm{O}_{10,3}$ & -689 & 86 & 98 & - & - & - & - \\
\hline Nitrocellulose 13,15\% N & 1.662 & $\mathrm{C}_{6} \mathrm{H}_{7,34} \mathrm{~N}_{2,65} \mathrm{O}_{10,3}$ & -687.4 & - & - & 85.98 & 84.35 & - & - \\
\hline Nitrocellulose 13,20\% N & 1.655 & $\mathrm{C}_{6} \mathrm{H}_{7,55} \mathrm{~N}_{2,45} \mathrm{O}_{9,9}$ & -707.8 & - & - & - & - & 20 & 28 \\
\hline
\end{tabular}




\begin{tabular}{|c|c|c|c|c|c|c|c|c|c|}
\hline Nitroglicerine (NG) (\%) & 1.6 & $\mathrm{C}_{3} \mathrm{H}_{5} \mathrm{~N}_{3} \mathrm{O}_{9}$ & -370.776 & - & - & 8.74 & 11.43 & 19 & 22.5 \\
\hline Nitroguanidine (NQ) (\%) & 1.77 & $\mathrm{CH}_{4} \mathrm{~N}_{4} \mathrm{O}_{2}$ & -95.336 & - & - & - & - & 54.70 & 47.60 \\
\hline Dinitrotoluene (DNT) (\%) & 1.52 & $\mathrm{C}_{7} \mathrm{H}_{6} \mathrm{~N}_{2} \mathrm{O}_{4}$ & -62.043 & 10 & - & - & - & - & - \\
\hline Dibutylphtalate (DBP) (\%) & 1.045 & $\mathrm{C}_{16} \mathrm{H}_{22} \mathrm{O}_{4}$ & -841.055 & 3 & - & 4.18 & - & 4.50 & - \\
\hline Diphenylamine (DPA) (\%) & 1.16 & $\mathrm{C}_{12} \mathrm{H}_{11} \mathrm{~N}_{1}$ & 137.083 & 1 & 1 & 1 & 1.28 & - & - \\
\hline Ethylcentralite (Centr. I) (\%) & 1.124 & $\mathrm{C}_{17} \mathrm{H}_{20} \mathrm{~N}_{2} \mathrm{O}$ & -105 & - & - & - & 2.84 & 1.50 & 1.50 \\
\hline Graphite (\%) & 2.1 & $\mathrm{C}$ & 0 & - & 0.1 & 0.1 & 0.1 & - & 0.1 \\
\hline Cryolite (\%) & 2.9 & $\mathrm{Na}_{3} \mathrm{AlF}_{6}$ & -3302 & - & - & - & - & 0.30 & 0.30 \\
\hline Potasium sulfate (\%) & 2.662 & $\mathrm{~K}_{2} \mathrm{SO}_{4}$ & -1437 & - & 0.9 & - & - & - & - \\
\hline
\end{tabular}

\subsection{Determination of the heat of explosion $\left(Q_{e}\right)$}

The heat of explosion is the most important parameter of propellant combustion and it is the result of the difference between the heat of formation of reactants $\left(\mathrm{H}_{\mathrm{fr}}\right)$ and the heat of formation of products $\left(\mathrm{H}_{\mathrm{fp}}\right)$. According to Hess Law, for a combustion reaction with $\mathrm{m}$ reactants and $\mathrm{n}$ products, the heat of explosion is calculated in Eq. 1:

$$
Q_{e}=\sum_{i=1}^{n} H_{\text {fproducts }}-\sum_{j=1}^{m} H_{\text {freactants }}
$$

Experimental determination of the heat of explosion is based on the change in temperature of the water contained in an adiabatic calorimeter. The combustion takes place in the calorimetric bomb, in isochoric conditions. In the case of propellants with $\mathrm{Q}_{\mathrm{e}}$ lower than $800 \mathrm{cal} / \mathrm{g}$, the determination is done by adding standard propellant. For the experiments, the authors used AVL 1805 adiabatic ballistic calorimeter with Beckman thermometer (precision of $0.01 \mathrm{~K}$ ), stirrer, calorimetric bomb of $25 \mathrm{~cm}^{3}$, vacuum pump and manometer. The ignition was made using electric igniters with known calorific equivalent. The calorimetric bomb is a sealed cell made of steel, having an insulated electric pin for ignition, and a stainless-steel crucible for loading the propellant. The calorimeter, the bomb and a schematic diagram of the instrumental equipment is shown in Figure 2.

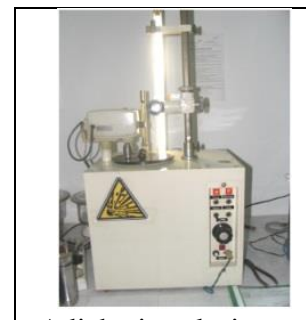

Adiabatic calorimeter AVL with electric ignition generator, variable stirrer and Beckman thermometer with focusing lens

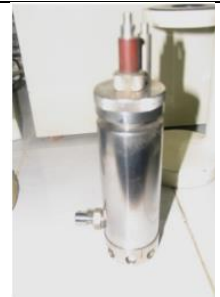

Calorimetric bomb with threaded seal lead, insulated terminal and gas venting valve

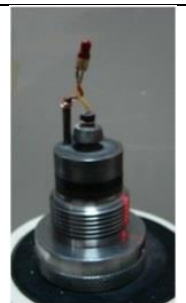

Calorimetric bomb seal threaded lead with electric igniter

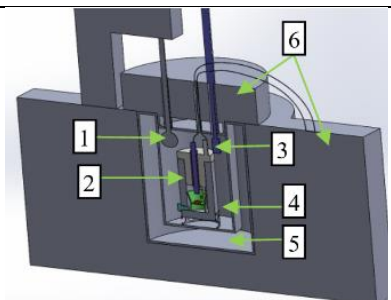

Schematically representation of an adiabatic calorimeter: 1-stirrer; 2-bomb; 3 -

thermometer; 4-water filled tank 11; 5-adiabatic air jacket; 6-insluated body

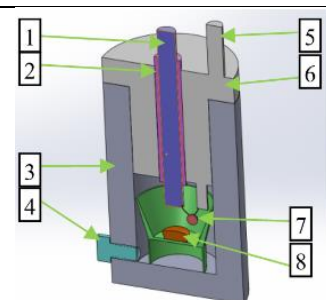

Schematically representation of a calorimetric bomb: 1-insulated terminal; 2-electric insulation;3-steel body; 4-gas vent; 5-ground terminal; 6sealed lead; 7-electric igniter; 8-propellant sample $2 \mathrm{~g}$

Figure 2. The instrumental setup used for determination of $\mathrm{Q}_{\mathrm{e}}$

For this determination, $10 \mathrm{~g}$ of each type of propellant was sampled and, if necessary, were grinded until the particles were under $5 \mathrm{~mm}$ in dimension. The resulting samples were dried for $2 \mathrm{~h}$ at $50^{\circ} \mathrm{C}$. After drying, the samples were cooled to ambient temperature in a desiccator for 1 hour, in the presence of dry calcium chloride. The used water was double distilled and conditioned to room temperature, for $24 \mathrm{~h}$. Each type of sample was divided in three batches of $2 \mathrm{~g}$ in order to do three parallel determinations. The samples were loaded in the calorimetric bomb and the electric igniter was mounted to the contacts. The lid was closed and sealed and a vacuum pump with manometer was connected to the venting valve (opened). The air was evacuated until a 130 - 400 Pa residual pressure was achieved. After this operation, the venting valve was close thus, maintaining vacuum in the chamber. The calorimeter was filled with water and the bomb was connected to impulse generator and then it was immersed using the special 
holder, avoiding contacting the walls of the calorimeter. On the Beckman thermometer temperature is read until the system stabilizes. Propellant is ignited and temperature is read at interval of $60 \mathrm{~s}$ until the indicator stabilizes at a final temperature. The heat of explosion is calculated with the following formula:

$$
Q_{e}=\frac{K \times \Delta t-q}{\omega}
$$

where $\mathrm{Q}_{\mathrm{e}}$ - heat of explosion (cal/g), K - caloric equivalent of the calorimeter $(1364,393 \mathrm{cal} / \mathrm{K}), \Delta \mathrm{t}$ difference between initial and final reads on the Beckman thermometer $(\mathrm{K}), \mathrm{q}$ - calorific equivalent of the electric igniter (cal), w - quantity of analyzed propellants (g). For the determination of $\mathrm{q}$, the Qeigniter $=716,32 \mathrm{cal} / \mathrm{g}$ of the electric igniter is divided to the mass of electric igniter. The experimental results are presented in Table 2.

\subsection{Determination of te specific volume $\left(V_{e}\right)$}

In addition to $\mathrm{Q}_{\mathrm{e}}$, another important parameter of the combustion of propellants is represented by the total number of moles of gaseous species generated by $1 \mathrm{~kg}$ of propellant. This parameter is calculated after determination of the chemical equilibrium in specific pressure and temperature conditions. The specific volume is defined as the total volume occupied in standard temperature and pressure conditions by the gaseous species generated by the combustion of $1 \mathrm{~kg}$ of propellant. Water moles are not included in this definition, but in ballistic conditions, gaseous water contributes to overall performance. The specific volume is defined in eq. 3 ( $\mathrm{n}_{\mathrm{i}}$ - the number of moles of $i$ gaseous species):

$$
V_{e}=22.4 \frac{l}{m o l} \times \sum n_{i}
$$

The experimental determination of the specific volume is made after the determination of the heat of explosion, by measuring the pressure rise in a constant volume, generated by venting the gaseous combustion products from the calorimetric bomb in a Julius-Peters gas meter. The apparatus is composed of a $3150 \mathrm{~cm}^{3}$ glass tube connected to a mercury manometer. Before determination, vacuum is created in the tube. The calorimetric bomb is connected to the tube and both the bomb vent and the tube valve are opened. The final pressure in the volume of the tube and the calorimetric bomb is used to calculate the specific volume of propellant, with the formula:

$$
V_{e}=\frac{W \times \Delta H \times 273.15}{\omega \times 760 \times(273.15+t)}-\frac{\omega_{i}}{\omega} \times V_{e i}
$$

where: $\mathrm{V}_{\mathrm{e}}$ - specific volume of the propellant $(1 / \mathrm{kg}), \mathrm{W}$ - the volume of the calorimetric bomb and the gas meter tube $\left(3175 \mathrm{~cm}^{3}\right), \omega$ - the mass of propellant $(\mathrm{g}), \mathrm{t}-$ ambient temperature $\left({ }^{\circ} \mathrm{C}\right), \omega_{i}$ - the mass of igniter used to initiate the propellant $(\mathrm{g}), \mathrm{V}_{\mathrm{ei}}$ - specific volume of the pyrotechnic composition of the electric igniter (previously determined $-184.59 \mathrm{l} / \mathrm{kg}$ ). The experimental setup is represented in Figure 3 and the experimental results are presented in Table 2.

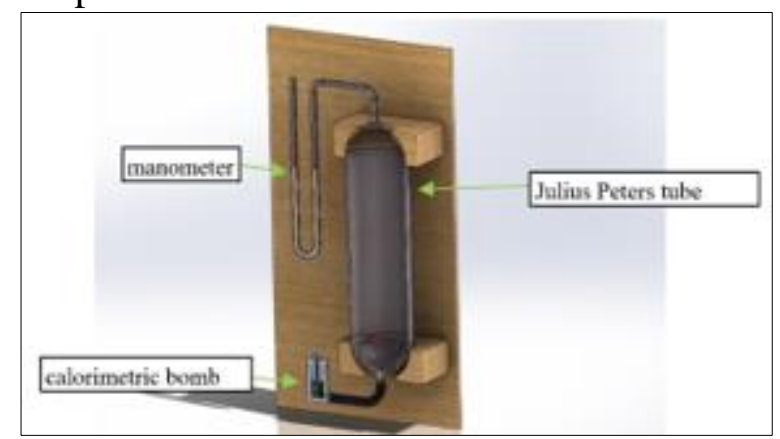

Figure 3. The instrumental setup used for determination of $\mathrm{V}_{\mathrm{e}}$ 
Table 2. Experimental determination of $\mathrm{Q}_{\mathrm{e}}$ and $\mathrm{V}_{\mathrm{e}}$ for the selected propellants

\begin{tabular}{|c|c|c|c|c|c|c|c|c|c|}
\hline 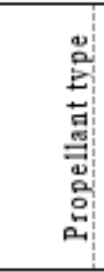 & 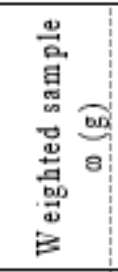 & 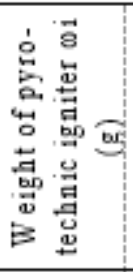 & 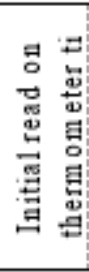 & 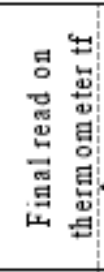 & & 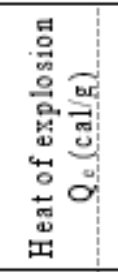 & 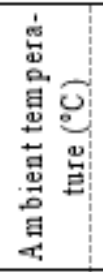 & 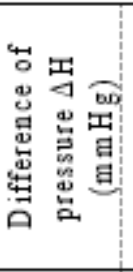 & 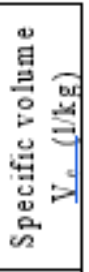 \\
\hline SB 1 & 1.986 & 0,184 & 2.36 & 3.56 & 1 & 761 & 21.2 & 472 & 904 \\
\hline & 1.989 & 0,215 & 2.30 & 3.53 & 1 & 766 & 22 & 484 & 921 \\
\hline & 1.981 & 0,177 & 2.62 & 3.80 & 1 & 750 & 21.7 & 484 & 929 \\
\hline \multicolumn{6}{|c|}{ Mean value } & 759 & \multicolumn{2}{|c|}{ Mean value } & 918 \\
\hline SB2 & 2.008 & 0,186 & 2.85 & 4.32 & 1 & 931 & 22 & 414 & 780 \\
\hline & 1.981 & 0,202 & 2.10 & 3.55 & 1 & 926 & 21.8 & 405 & 772 \\
\hline & 2.019 & 0,205 & 2.77 & 4.25 & 1 & 929 & 21.7 & 411 & 769 \\
\hline \multicolumn{6}{|c|}{ Mean value } & 929 & \multicolumn{2}{|c|}{ Mean value } & 774 \\
\hline \multirow[t]{3}{*}{ DB1 } & 2.007 & 0.203 & 2.67 & 4.20 & 1 & 969 & 21.3 & 436 & 824 \\
\hline & 2.003 & 0.201 & 2.83 & 4.35 & 1 & 965 & 21.7 & 455 & 862 \\
\hline & 1.984 & 0.200 & 2.49 & 3.95 & 1 & 933 & 21.6 & 432 & 825 \\
\hline \multicolumn{6}{|c|}{ Mean value } & 955 & \multicolumn{2}{|c|}{ Mean value } & 837 \\
\hline \multirow[t]{3}{*}{ DB2 } & 2.009 & 0.195 & 2.98 & 4.60 & 1 & 1033 & 21.3 & 416 & 784 \\
\hline & 1.991 & 0.185 & 2.25 & 3.82 & 1 & 1008 & 21.6 & 422 & 803 \\
\hline & 1.980 & 0.183 & 2.95 & 4.52 & 1 & 1017 & 21.1 & 420 & 806 \\
\hline \multicolumn{6}{|c|}{ Mean value } & 1020 & \multicolumn{2}{|c|}{ Mean value } & 798 \\
\hline \multirow[t]{3}{*}{ TB 1 } & 2.008 & 0.182 & 2.74 & 4.02 & 1 & 808 & 21.3 & 496 & 941 \\
\hline & 1.983 & 0.187 & 2.65 & 3.92 & 1 & 807 & 21.6 & 485 & 929 \\
\hline & 1.984 & 0.171 & 2.20 & 3.46 & 1 & 802 & 22.0 & 490 & 939 \\
\hline \multicolumn{6}{|c|}{ Mean value } & 806 & \multicolumn{2}{|c|}{ Mean value } & 936 \\
\hline \multirow[t]{3}{*}{ TB2 } & 1.987 & 0.199 & 2.65 & 4.18 & 1 & 978 & 21.0 & 419 & 800 \\
\hline & 2.020 & 0.193 & 2.99 & 4.55 & 1 & 982 & 21.3 & 432 & 811 \\
\hline & 2.006 & 0.218 & 2.48 & 4.02 & 1 & 970 & 21.9 & 424 & 797 \\
\hline \multicolumn{6}{|c|}{ Mean value } & 977 & \multicolumn{2}{|c|}{ Mean value } & 803 \\
\hline
\end{tabular}

\subsection{Combustion models}

\subsubsection{Kamlet - Jacobs model}

This is an empirical combustion model, which calculates the combustion products of detonation phenomena of CHNO explosives. It is based on the assumption that carbon oxidizes completely to carbon dioxide, without formation of carbon monoxide. The model is accurate with experimental determinations under high pressure and temperature conditions $[9,10]$. In this determination, the loading density is not taken into account, thus pressure and temperature do not influence the chemical composition of reaction products. The model for a propellant with $i$ components is stated in eq. 5 - 11:

$$
\begin{aligned}
& {\left[\begin{array}{cccccc}
C_{1 a} & H_{1 b} & N_{1 c} & O_{1 d} & n_{1} & H_{f 1} \\
C_{2 a} & H_{2 b} & N_{2 c} & O_{2 d} & n_{2} & H_{f 2} \\
\dot{C_{i a}} & H_{i b} & N_{i c} & O_{i d} & n_{i} & H_{f i}
\end{array}\right] \rightarrow C_{a} H_{b} N_{c} O_{d} ; \quad n_{i}=\frac{i(\%)}{100} \cdot \frac{1000}{M_{i}}(m o l) ;} \\
& a=\sum_{i} i a \cdot n_{i} ; M_{i}=12 \cdot i a+i b+14 \cdot i c+16 \cdot i d\left(\frac{g}{m o l}\right) \\
& C_{a} H_{b} N_{c} O_{d} \rightarrow x H_{2} O+y H_{2}+w C O_{2}+z O_{2}+u C_{(s)}+t N_{2} \\
& x=\min \left(\frac{b}{2}, d\right) ; y=\frac{b-2 x}{2} ; w=\min \left(\frac{d-x}{2}, a\right) ; z=\frac{d-x-2 w}{2} ; u=a-w ; t=\frac{c}{2} \\
& Q_{e}=x H_{f H 2 O(l)}+y H_{f C O 2}-\sum_{i} n_{i} H_{f i}\left(\frac{k J}{k g}\right)
\end{aligned}
$$




$$
V e=(y+w+z+t) \cdot V_{\operatorname{mol}(p, T)}\left(\frac{l}{k g}\right)
$$

Adiabatic flame temperature $\left(T_{f}\right)$ is calculated by iterative calculations, until convergence, starting from the relation:

$$
Q e=\sum_{i} n_{i} \cdot \int_{273.15}^{T_{f}} c_{p i}(T) d t
$$

where $c_{\mathrm{pi}}(\mathrm{T})$ is a function of temperature for the specific heat of product $i$. The function $\mathrm{c}_{\mathrm{pi}}(\mathrm{T})$ was developed by polynomial interpolation on intervals, from data available in [9].

\subsubsection{Le Chatelier - Millard model}

This empirical combustion model is designed for lower temperature and pressure conditions. It is based on the assumption that carbon oxidizes partially and the rest of the oxygen available is equally consumed by formation of water and complete oxidation of carbon monoxide to carbon dioxide. The model is tailored for combustion and deflagration processes in moderate confinement $\left(0.1-1 \mathrm{~g} / \mathrm{cm}^{3}\right)$ $[11,12]$. For an input matrix (calculated like in eq. 5 - 6) of propellant with $i$ CHNO components, the chemical composition of products is determined by eq. $12-15$. Heat of explosion, specific volume and adiabatic flame temperature are calculated in the same way like in eq. 9 - 11.

$$
\begin{aligned}
& \mathrm{C}_{a} \mathrm{H}_{b} \mathrm{~N}_{c} \mathrm{O}_{d} \rightarrow x C O+y C+b H+w O+v N_{2} \\
& x=\min (a, d) ; y=a-x ; w=d-x ; v=\frac{c}{2} \\
& x C O+y C+b H+w O+v N_{2} \rightarrow j C O+k C O_{2}+y C+\mathrm{mH}_{2} \mathrm{O}+n \mathrm{H}_{2}+o \mathrm{O}_{2}+v \mathrm{~N}_{2} \\
& j=x-\frac{w}{2} ; k=\frac{w}{2} ; m=\min \left(\frac{w}{2}, \frac{b}{2}\right) ; n=\frac{b-2 m}{2} ; o=\frac{(w-k-m)}{2}
\end{aligned}
$$

\subsubsection{Lagrange multiplier model}

This model is tailored to determine the chemical equilibrium composition in the oxidation-reduction reactions, specific to most of detonating systems, using the Lagrange multiplier model as a method of determining the restricted optimum. The method, applied to a plurality of chemical reactors to determine the values of the thermodynamic reaction characteristics, is a method based on reducing the degree of nonlinear systems, which describes the chemical reactions, to grade 1 by introducing an equivalent number of unknown coefficients. It is a method of calculating the optimum with constraints, the constraints being the equations for the conservation of atomic species that enter and exit the combustion/deflagration reaction. The model generates free enthalpy as a function of a gaseous mixture in given thermodynamic condition:

$$
\left(G_{T}\right)_{a m}=\sum_{i=1}^{N} R T x_{i}\left[\left(\frac{G_{T}^{0}}{R T}\right)_{i}+\ln p_{i}\right]=R T \sum_{i=1}^{N} x_{i}\left[\left(\frac{G_{T}^{0}}{R T}\right)_{i}+\ln \left(p \frac{x_{i}}{\sum_{i=1}^{N} x_{i}}\right)\right] \frac{1}{R T}
$$

For $\mathrm{R}$ product species, the matrix for equilibrium determination is like in eq. 17 :

$$
\left(\begin{array}{ccccc}
T_{0} & T_{1} & T_{2} & \cdots & T_{k} \\
\left(\frac{G_{T}}{R T}\right)_{0} & \left(\frac{G_{T}}{R T}\right)_{1} & \left(\frac{G_{T}}{R T}\right)_{2} & \cdots & \left(\frac{G_{T}}{R T}\right)_{R}
\end{array}\right)
$$

The model gives accurate results of the chemical composition of products as a function of temperature and pressure. The output parameters of the model (heat of combustion, specific volume and adiabatic flame temperature) are calculated in similar way with Kamlet - Jacobs model. Lagrange multiplier method is not restricted to CHNO propellants, offering the possibility to determine the reaction products of a complex propellant containing virtually any atomic species [13 - 15]. 


\section{Results and discussions}

\subsection{Chemical composition of combustion products}

The chemical composition of combustion products was calculated using Kamlet-Jacobs model (KJ), Le Chatelier - Millard (C-M) model and Lagrange multiplier method (L-M). In L-M method, the authors took into account all chemical species $\left(\mathrm{Na}_{3} \mathrm{AlF}_{6}, \mathrm{~K}_{2} \mathrm{SO}_{4}\right)$ present in the propellants. The model is also sensible to loading density, $0.08 \mathrm{~g} / \mathrm{cm}^{3}$ was used for calculations in order to be coherent with experimental determinations. The chemical composition, in number of moles of product per kilogram of propellant $(\mathrm{mol} / \mathrm{kg})$ is represented in Figure 4.

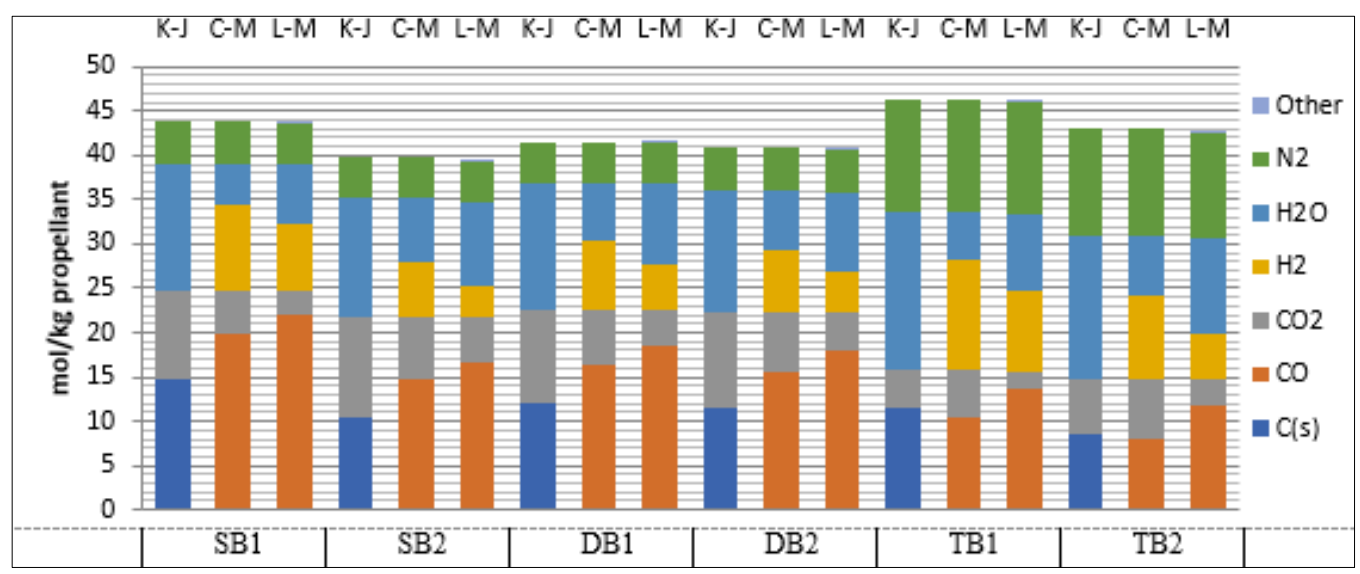

Figure 4. The chemical composition of combustion products

It can be observed that, in Kamlet-Jacobs model, the composition of combustion products is composed of 20 to $30 \%$ of solid carbon, which is evidently in contradiction to factual ballistic use of propellants. Arms and artillery barrels present negligible deposition of soot (amorphous carbon) in the barrels after firing dozens of projectiles. No hydrogen or other combustible species are present in the combustion gas, which also is in contradiction with the flame exhibited by combustion products, when exiting the muzzle and turbulently being mixed with air. The C-M model and the L-M method retrieve similar results in composition with the tendency in L-M model to form water in the detriment of carbon dioxide, based on the available oxygen. As a result, hydrogen is more abundant in CM model. The L-M model also retrieves small amounts $\left(>0.1 \mathrm{~mol} / \mathrm{kg}\right.$ ) of other combustion products $\left(\mathrm{KOH}, \mathrm{H}_{2} \mathrm{~S}, \mathrm{SO}_{2}, \mathrm{HF}\right.$, $\mathrm{Al}_{2} \mathrm{O}_{3}$ etc.) generated by the presence in the composition of additives or by reactions of atomic nitrogen $\left(\mathrm{NH}_{3} \mathrm{HCN}\right)$. The complete chemical composition of TB2 at $3037 \mathrm{~K}$ (flame temperature) and $2700 \mathrm{~atm}$ (pressure in the calorimeter bomb) is shown in Figure 5.

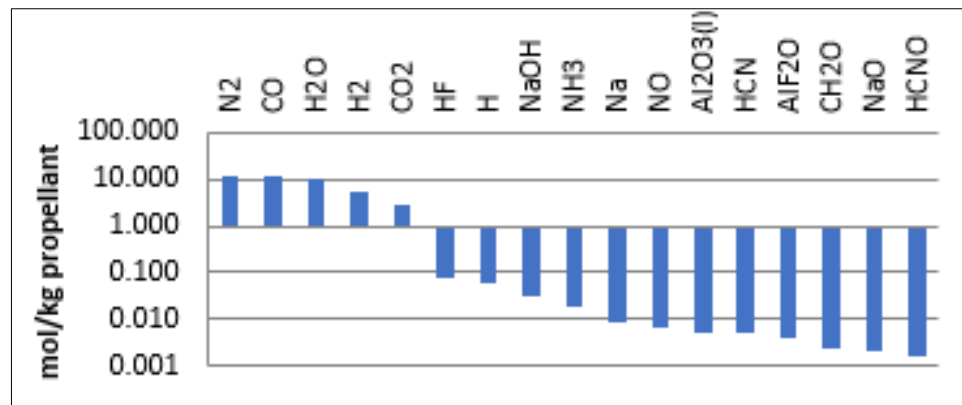

Figure 5. The chemical composition of combustion products of TB2 calculated according to L-M method

\subsection{Heat of explosion}

The heat of explosion was calculated using Kamlet-Jacobs model (K-J), Le Chatelier-Millard (C-M) model and Lagrange multiplier method (L-M). The results obtained were evaluated using the average 
$(A V G)$ value of the heat of explosion obtained by the experimental determination. Heat of formation for condensed water was used in the calculations, in order to be comparable to experimental results. The absolute values and the error of every calculation relative to the experimental AVG is presented in Figure 6.

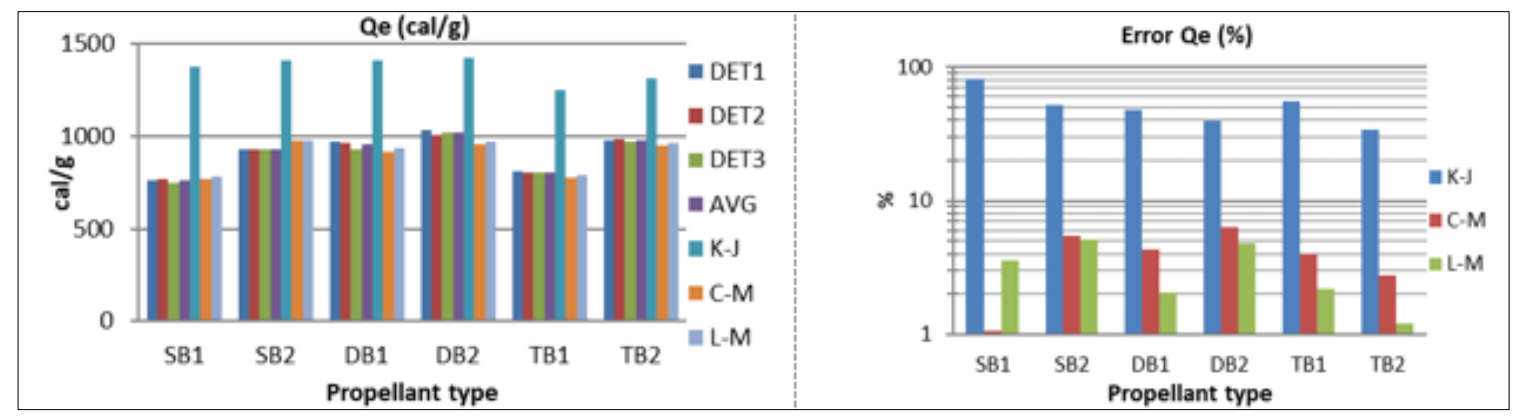

Figure 6. Heat of explosion from experimental and numerical determination (left) and the error of the combustion models (right)

The heat of explosion calculated by Kamlet-Jacobs model presents 40 to $80 \%$ higher value than the experimental average. The reason is caused by the model of combustion, the large amount of water formed, calculated in condensed state, gives an exaggerated exothermal reaction. C-M and L-M methods give satisfactory results in terms of heat of explosion, the error being under 5\% for both models. In the $\mathrm{Q}_{\mathrm{e}}$ graph, it can be observed a tendency of the model to overestimate the $\mathrm{Q}_{\mathrm{e}}$ for simple base propellants (SB) and to underestimate for double and triple base propellants (DB and TB).

\subsection{Specific volume}

The specific volume was calculated by multiplying the number of gaseous moles (excluding water) with the specific volume of a mol of gas for a pressure of 1 atm and $20^{\circ} \mathrm{C}(23.72 \mathrm{l} / \mathrm{mol})$. The absolute values and the error of every calculation relative to the experimental AVG is presented in Figure 7.
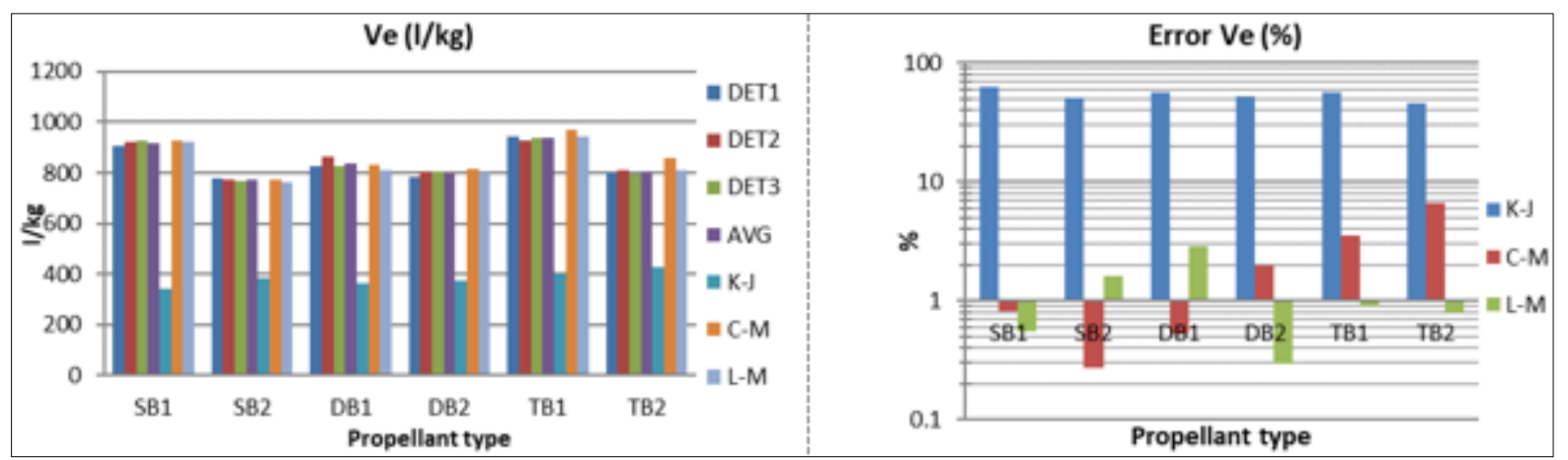

Figure 7. Specific volume from experimental and numerical determination (left) and the error of the combustion models (right)

Both Le Chatelier-Millard (C-M) model and Lagrange Multiplier (L-M) method show very close estimation of the specific volume for the tested propellants. There is a tendency of C-M model to overestimate $\mathrm{V}_{\mathrm{e}}$ for triple base propellants, probably because of the lower number of water molecules taken into account into the model (Figure 4), because, otherwise, both models give close results in terms of total number of gas moles. The Kamlet-Jacobs model returns values of $\mathrm{V}_{\mathrm{e}}$ with errors of 40 to $60 \%$. The reason for this error is the formation of amorphous carbon in high concentrations. 


\subsection{Flame temperature}

The adiabatic flame temperature was calculated using eq. 11 . The values are consistent with data found in sources [16 - 18]. The results of the calculations according to K-J, C-M and L-M models are presented in Figure 8.

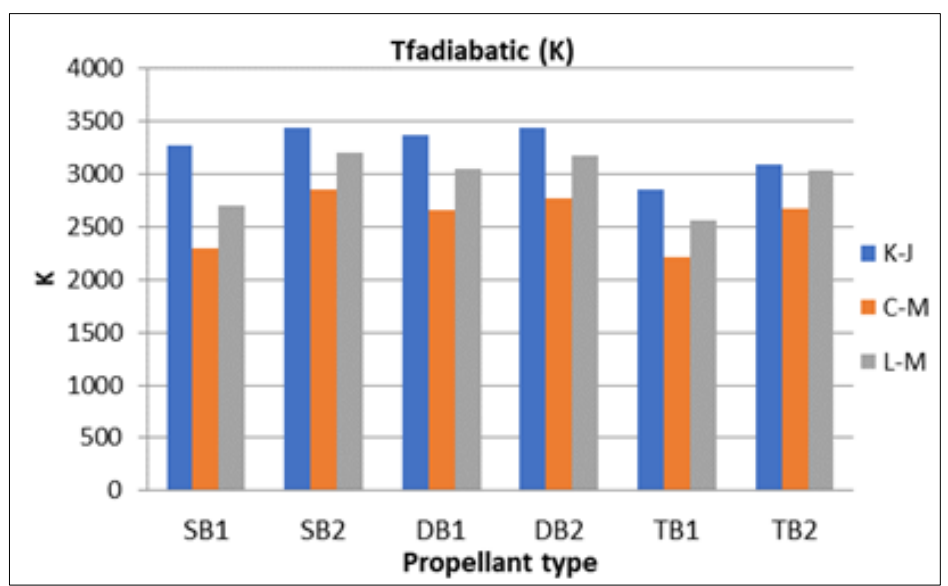

Figure 8. Adiabatic flame temperatures calculated for the six types of propellants analyzed

All values of $\mathrm{Q}_{\mathrm{e}}$ available from the combustion were consumed in the internal energy of the combustion products. In the experimental determination, the process is pseudo-adiabatic, as the combustion period extends from 10 to 40 milliseconds, time in which heat is lost into the calorimetric bomb steel cylinder. In the L-M model, temperature and pressure are key parameters in the determination of chemical equilibrium. The influence of pressure and temperature (based on a loading density of $0.08 \mathrm{~g} / \mathrm{cm}^{3}$ ) of propellant DB2 is presented in Figure 9.
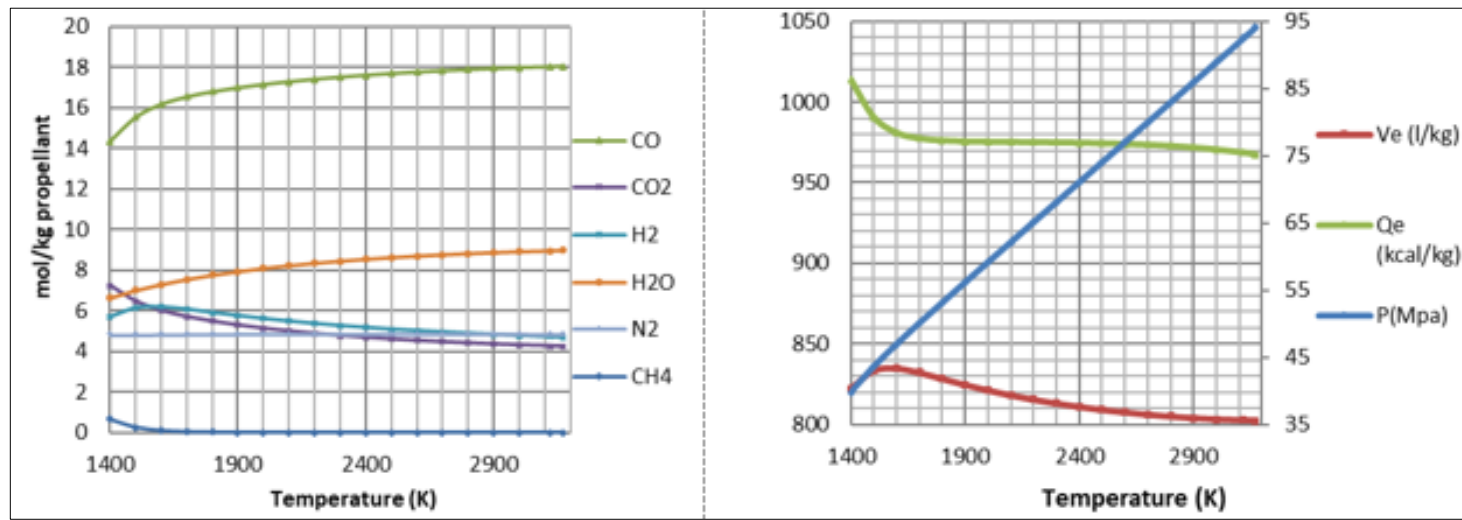

Figure 9. The chemical composition of combustion gases, $\mathrm{Q}_{\mathrm{e}}$ and $\mathrm{V}_{\mathrm{e}}$ for $\mathrm{DB}$, computed with L-M method

The heat of explosion $\left(\mathrm{Q}_{\mathrm{e}}\right)$ has an abrupt decrease in the interval of 1400 - $1600 \mathrm{~K}$, related to the formation of carbon monoxide in the detriment of carbon dioxide and methane. After $1600 \mathrm{~K}, \mathrm{Q}_{\mathrm{e}}$ stabilizes to $\approx 970 \mathrm{kcal} / \mathrm{kg}$, up to $3200 \mathrm{~K}$. The specific volume reaches a step maximum at $1600 \mathrm{~K}$, in relation with the maximum amount of molecular hydrogen present in the combustion gas. At lower temperatures, formation of a mole of methane consumes two moles of potential hydrogen molecules and over the temperature of $1600 \mathrm{~K}$, molecular hydrogen formation minimizes in favor of more heavy water molecule [19]. 


\section{Discussion on combustion models versatility}

The K-J, C-M and L-M models have been investigated in the capability to predict the chemical composition, heat of explosion and specific volume of combustion products of simple, double and triple base propellants. In Figure 10, the authors present the results obtained by applying the models to detonation of 2,4,6-trinitrotoluene (TNT). The pressure generated by this chemical transformation is two orders of magnitude higher than combustion of propellants (20 GPa for detonation, $200 \mathrm{MPa}$ for combustion of propellants). The models not sensible to pressure (K-J and C-M) tend to have big errors as compared to the reference values taken from [2] (KJ: 28\% and 17\% for $\mathrm{Q}_{\mathrm{e}}$ and $\mathrm{V}_{\mathrm{e}} ; \mathrm{C}-\mathrm{M}: 31 \%$ and $43 \%$ for $\mathrm{Q}_{\mathrm{e}}$ and $\mathrm{V}_{\mathrm{e}}$ ), while Lagrange Multiplier method retrieves very good results (error is $3.46 \%$ for $\mathrm{Q}_{\mathrm{e}}$ and $4.80 \%$ for $\mathrm{V}_{\mathrm{e}}$ ).

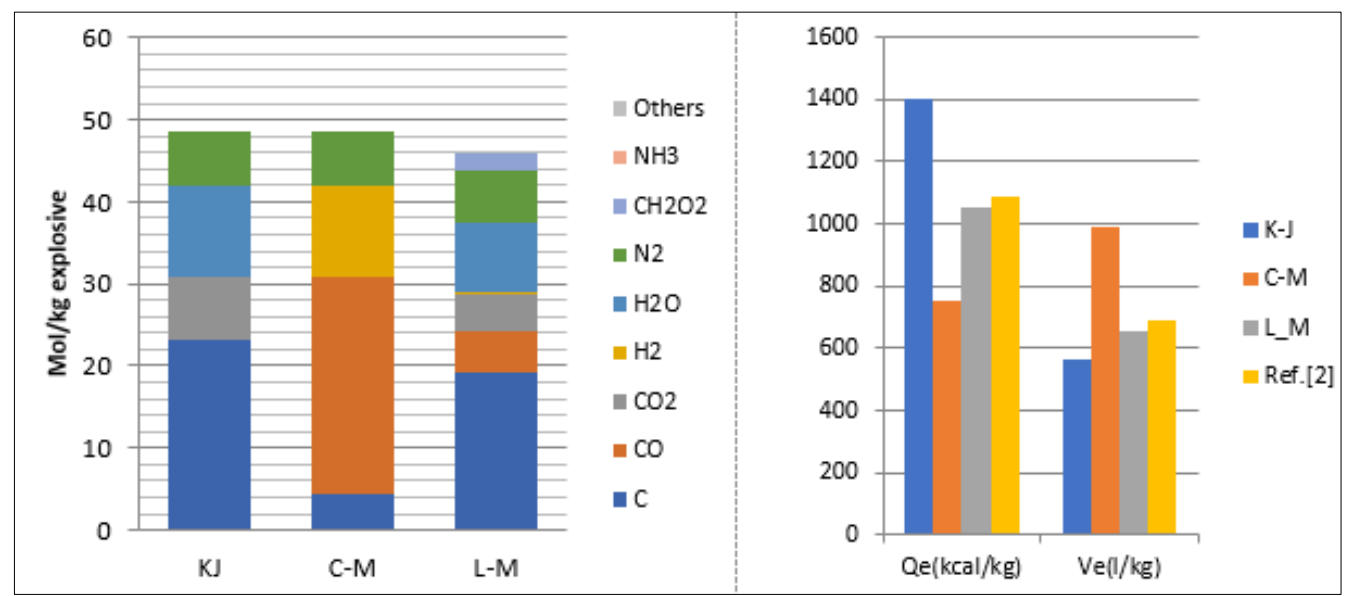

Figure 10. The chemical composition of combustion gases, $Q_{e}$ and $V_{e}$ for 2,4,6-trinitrotoluene (TNT), computed with K-J, C-M and L-M method

\section{Conclusions}

In this study, three models of combustion of nitrocellulose-based propellants were evaluated by experimental determinations of the heat of explosion $\left(\mathrm{Q}_{\mathrm{e}}\right)$ and the specific volume $\left(\mathrm{V}_{\mathrm{e}}\right)$. The chemical composition of the propellant is very important in the prediction of the performance parameters. The authors observed that triple base propellants give large amounts of heat and volume with moderate temperature. The L-M model is able to calculate the complete chemical composition of the combustion products, including atoms outside of CHNO energetic materials. This is important because some of the additives could generate important modifications in the $\mathrm{Q}_{\mathrm{e}}$ and $\mathrm{V}_{\mathrm{e}}$.

The heat of explosion was determined by experimentation for six types of propellants, using an adiabatic calorimeter coupled with a calorimetric bomb. The three parallel determinations proved that the method is precise enough to characterize a propellant material. The specific volume was determined using Julius-Peters device. The acquired experimental data were used in order to validate the theoretical calculations with the combustion models.

The complex L-M model proved to have the best results, being in very close accordance with the experimental results. The Le Chatelier-Millard (C-M) method also gives good results (under $7 \%$ error) for determination of $\mathrm{Q}_{\mathrm{e}}$ and $\mathrm{V}_{\mathrm{e}}$. The Kamlet-Jacobs model retrieves results with very high error. That is caused by the model being designed to predict chemical reactions in detonation regime.

The L-M model proves to be the most appropriate model for complex task of determination of detailed chemical composition of products of combustion, under specified pressure and temperature conditions. The model retrieves the resulting adiabatic temperature, heat of explosion, specific volume (number of gaseous moles/kg propellant) and chamber pressure based on the chemical composition of the propellant and the loading density as input parameters. 
Acknowledgments: This work was supported by a grant of the Romanian Ministry of Research and Innovation, CCCDI-UEFISCDI, project number PN-III-P2-2.1-PTE-2019-0463, within PNCDI III.

\section{References}

1. N. KUBOTA, Propellants and Explosives, Thermochemical aspects of combustion, Wiley-VCH GmbH, Weinheim, Germany, 2002;

2. T. ROTARIU, Chimia Explozivilor, Ed. Academia Tehnica Militara, Bucuresti, 2010;

3. T. TIGANESCU, T. ROTARIU, R. ESANU, T. ZECHERU, C. FLOREA, L. MATACHE, Studies Regarding the Effectiveness of Stabilizer "Revival" Process on Old Propellants, Rev. Chim., 65(9), 2014, $1042-104$

4. T. ROTARIU, T. TIGANESCU, R. ESANU, C. ENACHE, R. STEFĂNOIU, Researches on the Efficiency of Diphenylamine Addition to Aged Nitrocellulose Propellants, Rev. Chim., 64(9), 2013, 936 $-941$

5. W.B. SUDWEEKS, F.F. CHEN, M.D. MCPHERSON, Chemical Explosives and Rocket Propellants. In: Kent J.A. (eds) Kent and Riegel's Handbook of Industrial Chemistry and Biotechnology. Springer, Boston, USA, 2007;

6. W.N. KRISHNAMURTHY, T.L. VARGHESE, The chemistry and technology of solid rocket propellants, Allied Publishers Pvt. Ltd. New Delhi, 2017;

7. T.V. TIGANESCU, R. STEFANOIU, T. ROTARIU, M. LUPOAE, Aluminium Influence on Chemical Eequilibrium Composition Characteristics at Missile Fuel Burning, Rev. Chim., 58(7), 2007, 687-69

8. C. EVCI, H. ISIK, Analysis of the effect of propellant temperature on interior ballistics problem, Journal of Thermal Engineering, Vol. 4, No. 4, Special Issue 8, p. 2127-2136, Istambul, 2018

9. NIST Chemistry Webbook, SRD 69, https://webbook.nist.gov/chemistry/form-ser/;

10. P. POLITZER, J. Murray, The role of product composition in determining detonation velocity and detonation pressure, Central European Journal of Energetic Materials, 11(4), 2014, p. 459-474;

11. P. POLITZER, J. Murray, Some Perspectives on Estimating Detonation Properties

of C, H, N, O Compounds, Central European Journal of Energetic Materials, 8(3), 2011, p. 209-220;

12. A. OPPENHEIM, Detonations. In: Dynamics of Combustion Systems. Springer, Berlin, Heidelberg, 2008;

13. S. ŞTEFAN, GH. ALEXANDRU, T. PARASCHIV, I. CODREANU, Gazodinamica sistemelor reactante, Ed. AISM, Bucharest, 1994;

14. Y. WANG, J. A simple method for the prediction of the detonation performances of metal-containing explosives, Phys. Chem. A, 118 (25), 2014, p. 4575-4581;

15. D. FREM, The Use of the [H2O-CO2] Arbitrary Decomposition Assumption to Predict the Performance of Condensed High Explosives, Combustion, Explosion, and Shock Waves, 54, 6, 2018, p. 704-711;

16. S. WURSTER, Modellierung, simulation und charakterisierung des abbrandes extrudierbarer festtreibstoffe mit komplexer querschnittgeometrie., Prop., Explos., Pyrotech. 2017, 42, p. 736.

17. T. ROTARIU, R. PETRE, T. ZECHERU, M. SUCESKA, N. PETREA, S. EŞANU, Comparative study of $9 \times 19 \mathrm{~mm}$ ammunition combustion products and residues, Propellants, Explosives, Pyrotechnics, 40, 2015, p. 931-937;

18. Y. LI, W. YANG, S. YING, Burning characteristics of consolidated gun propellants, Propellants, Explosives, Pyrotechnics, 40, 2015, p. 33-38;

19. N.V. SUDARSAN, S.K. DAS, S.D. NAIK, Generalized method for gun propellant formulation design, Propellants, Explosives, Pyrotechnics. 2016, 41, p. 844.

Manuscript received: 31.03 .2020 